\title{
Legislação relativa à saúde mental: revisão de algumas experiências internacionais*
}

\author{
Mental health legislation: a review of some international experiences
}

José M. Bertolote

Divisão de Saúde Mental - Organizacão Mundial da Saúde - Suiça

\begin{abstract}
Apresenta-se atualizaçăo das principais áreas de interesse atual sobre a legislaçāo relativa à saúde mental, a saber: direitos dos doentes mentals (direito à assistência $\theta$ direitos humanos); qualidade da assistência; utilizaçāo da via administrativa $\theta$ do controle orçamentário; $\theta$ a participaçāo dos usúários na organização e administração dos serviços de saúde mentai. Com base em exemplos ałuallzados de modelos legislativos em várlas jurisdiçōes em alguns palses, descreve-se a evolução da legislação internacional referente às pesscas acometidas de doenças mentais, indica as tendéncias atuais $\theta$ aponta aiternativas para a melhoria da situação dos direitos humanos dos doentes mentais $\theta$ da qualidade da assistência que lhes é oferecida.
\end{abstract}

Saúde mental. Legislaçāo sanituria. Direitos humanos. Participaçâo comunitária.

\section{Introdução}

A Otganização Mundial da Saúde (OMS) é a agência da Organização das Naçōes Unidas (ONU) especializada em assuntos relativos à saúde. É uma organização intergovernamental sem poderes executivos que, no entanto, estabeleceu sólida reputação internacional como agência de cooperação técnica trabalhando com seus Países Membros num espírito de coesão e de consenso. Saúde Para Todos é sua política e sua estratégia principal é a de Cuidados Primários de Saúde.

A Divisāo de Saúde Mental da OMS tem como meta a redução dos problemas relacionados aos transtornos mentais e neurológicos bem como a facilitação da incorporação de habilidades, conhecimento e compreensão relativos a saúde mental aos cuidados gerais de saúde e ao desenvolvimento social. A pedra angular do Programa de Saúde Mental está apoiada na defesa de um desenvolvimento mental saudável e na promoção da saúde mental.
Nos últimos anos a Divisão de Saúde Mental observa e monitoriza grande aumento das atividades ligadas à legislaçāo relativa à saúde mental em nível internacional ${ }^{2}$. Não se trata aqui apenas de psiquiatria forense - da qual também se ocupa a Divisão de Saúde Mental - mas dos diferentes documentos legais que dizem respeito às pessoas diagnosticadas como doentes mentais: direitos humanos, direitos e responsabilidades civis, o código penal e os doentes mentais, limitações e restrições legais, normas de tratamento, entre outros.

Em vários países podem-se notar quatro áreas principais de interesse:

a) direitos dos doentes mentais;

- direito à assistência

- respeito aos seus direitos humanos

b) qualidade da assistência à saúde mental; 
c) uso adequado da via administrativa e do controle orçamentário; e

d) participação dos usuários na organização e na administração dos serviços de saúde.

\section{Direltos Humanos}

A Resolução $46 / 119$ de 17 de dezembro de 1991 aprovada pela Assembléia Geral da ONU'* sobre a proteção das pessoas com doenças mentais e a melhoria da assistência à saúde mental é um marco no campo dos direitos das pessoas com doenças mentais (Wachenfeld ${ }^{11}, 1992$ ).

Com efeito, esta $E$ a única Resolução da Assembléia Geral da ONU a abordar a assistência a um único grupo de doenças. Resoluções anteriores ja haviam abordado questठ́es dos direitos humanos em geral, de grupos especiais (crianças, incapacitados ou deficientes mentais), mas nunca havia abordado a questão dos direitos humanos e a assistência a um grupo específico de transtomos.

Esta Resolução teve suas origens nos anos 70 , quando a Comissāo dos Direitos Humanos da ONU passou a examinar a questão do abuso da psiquiatria para fins de controle de dissidentes políticos. O escopo do trabalho ampliou-se de uma preocupaçâo inicial com os critérios diagnósticos em uso em certos países para incluir o exame de maneiras de proteger os doentes mentais de fato $\mathrm{e}$, finalmente, maneiras de melhorar a assistência à saúde mental, em geral. Vários documentos de trabalho se sucederam (Relatórios Daes, Palley e Steele) culminando com o texto da Resolução finalmente aprovada em dezembro de $1991^{9}$.

A Resoluçăo 46/1 19 contém 25 Princípios (vide Anexo), vários dos quais subdivididos. Embora todos sejam igualmente importantes, vale a pena mencionar alguns deles que adquirem particular importância no que concerne a questāo dos direitos humanos.

\section{O Princípio 1.4 claramente estabelece que:}

"Nåo haverá discriminação sob alegaçăo de transtomo mental. 'Discriminaçāo'significa qualquer distinção, exclusão ou preferência que tenha o efeito de anular ou dificultar o desfrute igualitário de direitos."

\footnotetext{
* Existe cuidadosa versão em língua portuguesa produzida em 1992 pelo Programa de Saúde Mental da Secretaria Municipal de Saúde da Prefeitura do Municipio de Sāo Paulo, intitulada "A Proteçdo de Pessoas com Enfermidade Mental e a Melhoria da Assistência da Saúde Mental".
}

O mesmo Princípio segue especificando o direito de exercer todos os direitos civis, políticos, econômicos, sociais e culturais reconbecidos nos principais textos legais intemacionais como a Declaração Universal dos Direitos do Homem, a Convençăo Internacional de Direitos Econômicos, Sociais e Culturais, a Convenção Internacional de Direitos Civis e Políticos, a Declaração de Direitos da Pessoa Incapacitada e do Corpo de Princípios para a proteção de Todas as Pessoas sob Qualquer Forma de Detenção ou Aprisionamento ${ }^{10}$.

Os termos desse Princípio podem ter conseqüências notáveis quando explicitamente incluídos no texto da Constituição ou do Código Civil, como é o caso da Espanha, de Moçambique e, mais recentemente, da Província do Québec, no Canadá.

Outro ponto importante diz respeito à distinçāo a ser feita entre internaçāo involuntária e tratamento involuntário. Em primeiro lugar, nenhum tratamento (involuntário) poderá ser imposto a paciente de intemação voluntária; em segundo lugar, um tratamento involuntário só poderá ser imposto a paciente quando atenda ao maior interesse de suas necessidades de saúde. Aindâ, a internação só poderá se efetuar mediante determinação, por profissional de saúde mental qualificado e autorizado por lei para este fim, que a pessoa tem uma enfermidade mental, com uma séria possibilidade de dano imediato ou iminente à própria pessoa ou a outros, ou em caso de risco de séria deterioração de sua condiçâo. Finalmente, o acesso a um estabelecimento de saúde mental será processado da mesma maneira que o acesso a qualquer outro estabelecimento de saúde, o que significa que qualquer paciente voluntário deve ser livre para sair do hospital quando o desejar, sem restriçбes.

Em geral, na prática psiquiátrica habitual a importância da internação prevalece sobre a do tratamento. Os termos desses Princípios claramente invertem a ordem habitual desta prática, colocando o interesse do tratamento adiante do valor social da detençāo (internação). Tal se verifica na Itália ${ }^{8}$, por exemplo, onde a internaçāo só pode ser justificada como uma necessidade para efetuar um determinado tratamento, e nāo como justificada por si só.

\section{Saúde Pública e Direitos Humanos}

Um problema crucial em relação à questão dos direitos humanos dos portadores de diagnós- 
ticos de doença mental é o antagonismo entre o enfoque da Saúde Pública e o dos Direitos Humanos $^{3}$. Enquanto o primeiro se preocupa prioritariamente com a maioria da população, opera em nivel coletivo e privilegia a equidade, o segundo se preocupa fundamentalmente com a exceção, opera em nível individual e insiste em igualdade.

Estes dois enfoques distintos vêm-se influenciando mutuamente. No que diz respeito especificamente à saúde mental, várias soluçōes provisórias de compromisso têm sido encontradas em diferentes lugares, com a predominância ora de um, ora de outro enfoque, segundo os valores técnico-científicos e político-ideológicos prevalentes em cada lugar. Está longe, no entanto, a solução desta contradição operacional. A complicar esta questão está o fato de que com frequiência se englobam os chamados direitos civis com os direitos sociais, outra soluçāo provisória de compromisso político claramente refletida na mencionada Resolução da $\mathrm{ONU}^{4,5}$, e que já está a receber críticas 6 .

\section{Qualidade da Atençăo à Saúde Mental}

Outra tendência observada diz respeito à qualidade dos cuidados de saúde mental oferecidos ${ }^{1}$. A mencionada resolução com efeito aborda alguns padrōes de cuidados (Princípios 8-10, 13 e 14). As normas relativas aos criterios de formaçāo de profissionais, existentes em vários países, é um outro exemplo desta tendência.

Nos últimos dois anos a Divisão de Saúde Mental da OMS vem desenvolvendo uma série de instrumentos para a garantia da qualidade da assistência à saúde mental, cobrindo desde a política de saúde mental e do programa de saúde mental até os diversos tipos de serviços gerais e especializados. Esses instrumetnos foram testados em 14 países e já se encontram traduzidos em vários idiomas, inclusive o Português ${ }^{13}$.

\section{Uso da via Administrativa}

A formulaçāo de normas para garantir a qualidade da atençăo prestađa $\varepsilon$ um importante elemento para a elevação dos padrōes de qualidade dos serviços. A normatizaçăo pode ter um papel importante na superaçāo de eventuais impasses ideológicos, como o que opõe defensores e opositores tanto do hospital psiquiátrico como de modelos de saúde mental comunitária. $O$ que fínalmente é de maior importância para os usuários dos serviços é a qualidade dos serviços prestados, o respeito de seus direitos e a melhoria da qualidade de suas vidas, e não apenas o local onde os cuidados são prestados.

Importantes modificações de orientaçōes assistenciais podem ser obtidas, por exemplo, através do financiamento de modalidades de serviços que se quer desenvolver em detrimento de outros que se pretenda desestimular.

A utilização adequada de normas, com uma estratégia de avaliação que inclua a auto-avaliação e a participação dos usuários, pode representar uma enorme vantagem tanto do ponto de vista de tempo como de fortalecimento da posição e do respeito aos direitos dos usuários.

\section{Participação dos Usuárlos na Organlzação e na Adminlstração dos Serviços de Saúde}

Como parte de um processo mais global de democratizaçāo ${ }^{7}$, observa-se uma crescente participaçāo de usuários de serviços de saúde mental (pacientes, ex-pacientes e seus familiares) no planejamento e na implementação de serviços. Na maior parte estigmatizadas, rejeitadas e marginalizadas, as pessoas acometidas de doenças mentais começam a participar dos processo decisórios que a elas se referem e a adquirir maior poder de controle sobre os mesmos.

Nos últimos anos observa-se um crescente reconhecimento da capacidade que as pessoas têm para desempenhar um papel mais ativo em relação a decisỏes sobre práticas de cuidados de saúde que as afetam direta ou indiretamente. Com efeito, a Declaraçāo de Alma-Ata ${ }^{14}$ afirma em seu Artigo 4:

"as pessoas têm o direito e o dever de participar individual e coletivamente do planejamento e da implementação da assistência à sua saúde."

Da mesma forma, a participação individual nos processos comunitários e nacionais é também um importante direito e responsabilidade. A participação comunitária é particularmente estimulada pela Declaração de Alma-Ata:

"a participação comunitária representativa deveria ser a regra em todos os organismos oficiais que lidam com a saúde. Deve-se ter o cuidado de incluir representantes tanto dos grupos vulneráveis 
como dos grupos que demonstrarem iniciativa e urn interesse particular em melhorar a saúde das comunidades."

Uma participação equilibrada e responsável pode ser obtida através da inclusão dos seguintes setores 12 :

- usuários e ex-usuários;

- familiares;

- grupos comunitários (p.ex.: grupos religiosos, de mulheres, de jovens, de minorias étnicas, e outros);

- governo local;

- organizações científicas;

- organizações de profissionais da saúde; sindicatos;

grupos de auto-ajuda;

- grupos e agências comunitárias de apoio às pessoas acometidas de doenças mentais.

Desta forma, a participação individual e comunitária deveria ser encorajada por meio de disseminação de informação apropriada e da remoção de barreiras institucionais desnecessárias que impedem a plena participação de indivíduos, famílias e comunidades.

\section{Referências Blbliográficas}

1. BERTOLOTE, J.M. Quality assurance in mental health care. In: Sartorius, $V_{1}$ ed, et al. Treatment of mental disorders. Washington, APA, 1993, p.443-61.

2. BERTOLOTE, J.M. Mental health legislation in Europe: England, Scotland, Spain, France and Italy. Int. Dig. Health Leg, 42:396-7, 1991.

3. BERTOLOTE, JM. The human rigths of the mentally ill in Europe under the European Convention on Human Rights. Int. Dig. Healtb Leg., 45: 618-20, 1994.

4. BRODY, E. Biomedical tecbnology and buman rights. Paris, LNESCO, 1993.

5. GENDREAU, C. Elaboration d'une nouvelle norme interrationalle concernant le droit du patiente psychiatrique de consentir à un traitement ou de le refuser. Montreal, 1994 [Master of Law Thesis, Université de Montreal].

6. KRAUTHAMMER, C. Human rights: giving in after the debate in won. Int. Herald Tribune, June 19-20, 1993. p.4.

7. MERKL, P.E. Which are today's democracies? Int. Soc. Sci.J., 136: 257-70, 1993.

\section{Conclusões}

A experiência de vários países no campo da legislação de saúde mental mostrou que no caso de leis principais (por exemplo, lei nacional de saúde mental, códigos civis ou penais), o tempo transcorrido entre uma injcjativa para seu desenvolvimento ou modificação substancial e sua aplicação é de aproximadamente dez anos, em média. De fato. em muitos cașos a promulgação de muita lei importante tem sido a confirmação - muitas vezes tardia - de mudanças já ocorridas na prática.

Por outro lado, regulamentações emanadas de autoridades administrativas podem introduzir importantes modificações, a curto prazo, desde que essas não estejam em contradição com alguma lei maior. Essa via é particularmente eficiente quando as autoridades de saúde em questão dis pōem do controle orçamentário.

Em suma: a via legisłativa maior é lenta, porém pode representar o envolvimento de amplos e variados segmentos da sociedade, enquanto que a via administrativa, que envolve menor número de pessoas, pode produzir os resultados desejados em muito menos tempo.

8. TANSELLA, M. \& WILLIAMS, P. The Italian experience and its implications. Psycbol. Med., 17: 283-9, 1987.

9. UNITED NATIONS GENERAL ASSEMBLY. The protection of persons with mental illness and the improvement of mental health care. Int. Dig. Health Leg., 43:413-23, 1992.

10. UNITED NATIONS, Human rights: a compilation of intemational instruments. New York. United Nations, 1994.

11. WACHENFELD, M. The human rights of the mentally ill in Europe under the European Convention on Human Rights. Nord. $J$. Int. Law, p.109-292, 1992.

12. WORLD HEALTH ORGANIZATION, Consumer involvement in mental bealth and rebabilitation services. Geneva, WHO, 1989. (Doc.: WHO/MNH/MEP/89.7).

13. WORLD HEALTH ORGANIZATION, Quality assurance in mental bealtb care. Geneva WHO, 1994. (Doc.: WHO/MNH/MND/94.17).

14. WORLD HEALTH ORGANIZATION/LNICEF. Primary bealth care: report of the International. Conference on Primary Health Care, Alma-Ata, LRSS, 1978. Geneva, 1978. 


\begin{abstract}
The main areas dealt with by current mental health legisiation, woridwide, are reviewed. These areas concem mainly: (i) rights of the mentally ill (right to care and human rights). (ii) quality of care, (iii) the use of administrative and budget control measures, and (iv) consumer perticipation and involvement in the orgenization and management of mental health care services. The evolution of intemational legisiation (particularly United Nations Declarations, Covenants and Resolutions) relative to people with mental disorders are described on the besis of up-to-date examples of legal models from different jurisdictions throughout the world. The main current trends are identified and altematives are advanced for the respect of the human rights of these people and for the improvement of their care. The basis for these proposed altematives is to be found in the recently approved United Nations General Assembly Resolution on "The protection of persons with mental illness and the improvement and the improvement of mental health care". This fiesolution is described and discussed in some detall.
\end{abstract}

Mental health. Legislation, health. Human rights. Consumer participation.

Anexo - Títulos principais da Resolução 46/119, de 17 de dezembro de 1991 da Assembléia Geral da Organizaçāo das Naçōes Unidas sobre a proteçāo de pessoas acometidas de transtomo mental e a methoria da assisténcia à saúde mental

Princípio 1: Liberdades fundamentais e direitos básicos

Princípio 2: Proteção de menores

Princípio 3: Vida em comunidade

Princípio 4: Determinação de um transtorno mental

Principio 5: Exame médico

Principio 6: Confidencialidade

Princípio 7: O papel da comunidade e da cultura

Princlpio 8: Padrāo de assistência

Princípio 9: Tratamento

Princípio 10: Medicaçăo

Principio 11: Consentimento para o tratamento

Princípio 12: Informação sobre os direitos

Princípio 13: Direitos e condiçōes de vida em estabelecimentos de saúde mental

Princípio 14: Recursos disponiveis nos estabelecimentos de saúde mental

Princípio 15: Princípios para a admissão

Princípio 16: Admissāo involuntária

Principio 17: Corpo de revisão

Princípio 18: Salvaguardas processuais

Princípio 19: Acesso à informaçāo

Principio 20: Dos infratores da lei

Principio 21: Queixas

Princípio 22: Monitoramento e mecanismos de intervenção

Princípio 23: Implementação

Princípio 24: Alcance dos princípios relacionados aos estabelecimentos de saúde mental

Princípio 25: Proteçāo dos direitos existentes. 